\title{
Circulating miR-145 as a Marker of Therapeutic Response to Anti- TNF Therapy in Patients With Ankylosing Spondylitis
}

\author{
Klára PRAJZLEROVÁ ${ }^{1,2}$, Martin KOMARC ${ }^{3}$, Š́rka FOREJTOVÁ ${ }^{1,2}$, Karel PAVELKA ${ }^{1,2}$, \\ Jiří VENCOVSKÝ ${ }^{1,2}$, Ladislav ŠENOLT ${ }^{1,2}$, Mária FILKOVÁ ${ }^{1,2}$ \\ ${ }^{1}$ Institute of Rheumatology, Prague, Czech Republic, ${ }^{2}$ Department of Rheumatology, First Faculty \\ of Medicine, Charles University, Prague, Czech Republic, ${ }^{3}$ Department of Anthropometrics and \\ Methodology, Faculty of Physical Education and Sport, Charles University, Prague, Czech \\ Republic
}

Received July 15, 2020

Accepted February 11, 2021

Epub Ahead of Print March 8, 2021

\section{Summary}

Circulating miRNAs appear promising therapeutic and prognostic biomarkers. We aimed to investigate the predictive value of circulating miRNAs on the disease outcome following anti-TNF therapy in patients with ankylosing spondylitis (AS). Our study included 19 AS patients assessed at baseline (M0), after three (M3) and twelve months (M12) of therapy. Total RNA was isolated from plasma. A comprehensive analysis of 380 miRNAs using TaqMan Low Density Array (TLDA) was followed by a single assay validation of selected miRNAs. All AS patients had high baseline disease activity and an excellent response to anti-TNF therapy at M3 and M12. TLDA analysis revealed the dysregulation of 17 circulating miRNAs, including miR-145. Single assay validation confirmed that miR-145 is significantly downregulated at M3 compared to baseline. The decrease in the levels of miR-145 from M0 to M3 negatively correlated with the change in BASDAI from M0 to M3; and positively correlated with disease activity improvement from M3 to M12 as per BASDAI and ASDAS. The predictive value of the early change in miR-145 and levels of miR-145 at M3 were further validated by Receiver operating curves analysis. We show that the early change in circulating miR-145 may be a predictor for the future outcome of AS patients treated with TNF inhibitors. Patients with a more significant decrease in miR-145 levels may show further significant improvement of disease activity after 12 months. Monitoring the expression of miR-145 in plasma in AS patients may, therefore, influence our therapeutic decision-making.

\section{Key words}

miRNA • Ankylosing spondylitis • anti-TNF therapy • Biomarker

\section{Corresponding author}

K. Prajzlerová, Institute of Rheumatology, Na Slupi 4, 12800 Prague, Czech Republic. Email: prajzlerova@revma.cz

\section{Introduction}

Ankylosing spondylitis (AS) is a chronic inflammatory disease that mainly affects the axial skeleton and typically presents with inflammatory back pain (Taurog et al. 2016). Inflammatory back pain, reduced mobility of the spine, and radiographic evidence of sacroiliitis are all part of the modified New York diagnostic criteria for AS (van der Linden et al. 1984). The new ASAS (The Assessment of SpondyloArthritis International Society) classification criteria for axial spondyloarthritis (AxSpA) use magnetic resonance imaging (MRI) of sacroiliac joints to detect spinal inflammation in patients with the non-radiographic stage of the disease and to enable earlier diagnosis (Rudwaleit et al. 2009). The most widely used tool for measuring disease activity of patients with AS is the BASDAI (Bath Ankylosing Spondylitis Disease Activity Index) that reflects the disease activity from the patient's perspective (Garrett et al. 1994). Later, the ASDAS (Ankylosing Spondylitis Disease Activity Score) for the assessment of disease activity was developed (Lukas et al. 2009). This includes C-reactive protein (CRP) or erythrocyte sedimentation rate (ESR) as laboratory markers of disease activity. The worsening of spinal mobility is influenced by inflammation in the early disease and structural 
damage in the radiographic phase (Machado et al. 2010). The first evidence of good treatment response to antiTNF (tumor necrosis factor) agents in patients with AS was described almost 20 years ago (Brandt et al. 2000). Current data suggest that the early initiation of therapy may reduce the radiographic progression in AS (Haroon et al. 2013). Significant improvement of disease activity, functional outcomes and inhibition of radiographic progression have been shown in patients treated with anti-TNF biologic drugs (Taurog et al. 2016).

There are several biomarkers of activity or treatment response being tested in AxSpA, but more studies in large patient cohorts are needed for their implementation in the clinical practice (Prajzlerova et al. 2016, Prajzlerova et al. 2017). CRP remains the best circulating marker for assessing disease activity and predicting treatment response and structural progression (Prajzlerova et al. 2016). MicroRNA (miRNAs) are small, non-coding RNAs important for posttranscriptional regulation of gene expression. Moreover, cell-free circulating miRNAs are released from the cells, are stable in body fluids, and may serve as promising therapeutic and prognostic biomarkers, e.g., in rheumatoid arthritis, AxSpA, or other non-rheumatic diseases (Filkova et al. 2014, Hruskova et al. 2016, Prajzlerova et al. 2017, Dlouha and Hubacek 2017). We have previously presented circulating miRNAs as markers of spinal involvement and disease activity in patients with AxSpA (Prajzlerova et al. 2017). The aim of the current study was to investigate miRNAs as predictors of treatment response to anti-TNF therapy in patients with AS.

\section{Methods}

\section{Patients}

This study included 19 patients who fulfilled the New York classification criteria for AS (van der Linden et al. 1984): 3 patients had stage I AS, 2 had stage II AS, 4 had stage III AS, 9 had stage IV AS, and 1 had a bamboo spine - stage V AS (Braun et al. 2002). All patients commenced treatment with anti-TNF therapy: 6 received infliximab, 3 adalimumab, 5 golimumab, and 5 were treated with etanercept. Clinical and laboratory parameters of disease activity were assessed using BASDAI (Garrett et al. 1994), ASDAS-CRP (Lukas et al. 2009), ESR and CRP at baseline (M0) prior to the start of treatment and after three (M3) and twelve months (M12) of therapy. Clinical characteristic is provided in
Table 1. Patients were recruited from the outpatient clinic of the Institute of Rheumatology in Prague. Written informed consent was obtained from all participants prior to enrolment. The study was approved by the local Ethics committee at the Institute of Rheumatology in Prague.

\section{Samples and RNA isolation}

Whole blood samples collected in EDTA tubes were obtained from all participants at baseline, at M3 and M12 of therapy. Plasma was separated by centrifugation within four hours of collection, ensuring constant preanalytical conditions for all samples. All plasma samples were stored at $-80{ }^{\circ} \mathrm{C}$, and no freeze-thaw cycles occurred before use. Total RNA, including the miRNA fraction, was extracted from plasma samples $(100 \mu l)$ using miRNeasy Serum/Plasma Kit (Qiagen, Düsseldorf, Germany) according to manufacturer's instructions. Spike-in non-human synthetic miRNA (C. elegans celmiR-36, cel-miR-54, and cel-miR-238, Integrated DNA Technologies, Coralville, IA, USA) were added to the samples after the initial denaturation for further normalization. Total RNA was eluted in $24 \mu$ l of RNasefree water and stored at $-80^{\circ} \mathrm{C}$. Total RNA concentration was measured using a NanoDrop 2000c spectrophotometer (Thermo Fisher Scientific, Waltham, MA, USA) in all samples.

\section{miRNA expression analysis}

First, non-pooled individual plasma RNA samples (M0, M3, and M12 from randomly selected 3 patients) were used. Complementary DNA was obtained by reverse transcription using a TaqMan $\AA$ MicroRNA Reverse Transcription Kit with Megaplex RT Primers (Thermo Fisher Scientific) with equal RNA input. cDNA was preamplified using $2 \mathrm{x}$ TaqMan ${ }^{\circledR}$ PreAmp Master Mix and Megaplex ${ }^{\mathrm{TM}}$ PreAmp Primers (all Thermo Fisher Scientific) on a PCR thermocycler (Bio-Rad Laboratories, Hercules, CA, USA). The expression of 380 miRNAs was measured using Human Pool A TaqMan ${ }^{\circledR}$ Low Density Array (TLDA) platforms for microRNAs on QuantStudio 7Flex Real-Time PCR System (Thermo Fisher Scientific). All steps were performed according to the manufacturer's instructions. The $\mathrm{dCt}$ method was used for relative quantification as follows: $\mathrm{dCt}=\mathrm{Ct}$ (array average)- $\mathrm{Ct}($ miRNA of interest), followed by $\mathrm{x}$-fold change calculations.

For further single assay validation, total RNA from 19 non-pooled samples was reverse-transcribed using TaqMan Real Time miRNA specific primers 
Table 1. Clinical characteristics of patients with ankylosing spondylitis

\begin{tabular}{|c|c|c|c|c|}
\hline Variable & M0 & M3 & M12 & $P$ value \\
\hline Gender; Female/Male & $6 / 13$ & - & - & NA \\
\hline Age; years & $38.16[15.22]$ & - & - & NA \\
\hline HLA-B27 positivity; $n(\%)$ & $19(100 \%)$ & - & - & NA \\
\hline$C R P ; m g / l$ & $22.61[29.47]$ & $3.09[8.01]$ & $3.96[5.70]$ & $<0.001^{\mathrm{a}, \mathrm{b}} \mathrm{NS}^{\mathrm{c}}$ \\
\hline$E S R ; m m / h$ & $36[26]$ & $6[18]$ & $11[23]$ & $<0.001^{\mathrm{a}, \mathrm{b}} \mathrm{NS}^{\mathrm{c}}$ \\
\hline$B A S D A I$ & $6.45[3.05]$ & $2.40[1.92]$ & $1.67[1.40]$ & $<0.001^{\mathrm{a}, \mathrm{b}} \mathrm{NS}^{\mathrm{c}}$ \\
\hline$A S D A S-C R P$ & $4.15[0.93]$ & $2.28[0.92]$ & $1.63[0.84]$ & $<0.001^{\mathrm{a}, \mathrm{b}} \mathrm{NS}^{\mathrm{c}}$ \\
\hline \multicolumn{5}{|l|}{ Anti-TNF therapy; $n(\%)$} \\
\hline Adalimumab & $3(16 \%)$ & - & - & NA \\
\hline Infliximab & $6(32 \%)$ & - & - & NA \\
\hline Golimumab & $5(26 \%)$ & - & - & NA \\
\hline Etanercept & $5(26 \%)$ & - & - & NA \\
\hline \multicolumn{5}{|l|}{ AS stage; $n(\%)$} \\
\hline Stage I & $3(16 \%)$ & - & - & NA \\
\hline Stage II & $2(10 \%)$ & - & - & NA \\
\hline Stage III & $4(21 \%)$ & - & - & NA \\
\hline Stage IV & $9(48 \%)$ & - & - & NA \\
\hline Stage V & $1(5 \%)$ & - & - & NA \\
\hline
\end{tabular}

Abbreviations: AS, ankylosing spondylitis; ASDAS, Ankylosing Spondylitis Disease Activity Score; BASDAI, Bath Ankylosing Spondylitis Disease Activity index; CRP, C-reactive protein; ESR, Erythrocyte Sedimentation Rate; NA, not applicable; NS, not significant; Data are presented as a median and interquartile range [IQR]. a, comparison between M0 and M3; b, comparison between M0 and M12; c, comparison between M3 and M12.

(including cel-miR-39, cel-miR-54, and cel-miR-238) and then amplified by real-time PCR with TaqMan probes and TaqMan Universal PCR Master Mix on QuantStudio 7 Flex Real-Time PCR System (all Thermo Fisher Scientific). The $\mathrm{dCt}$ method was used for relative quantification as follows: $\mathrm{dCt}=\mathrm{Ct}$ (spike-in average)$\mathrm{Ct}$ (miRNA of interest); higher $\mathrm{dCt}$ values represent the higher expression of particular miRNAs. All data were analyzed with QuantStudio 7 Flex Real-Time PCR System Software (Thermo Fisher Scientific).

\section{ELISA}

The levels of VEGF in plasma were measured using a commercially available ELISA kit (Human VEGF Quantikine ELISA, R\&D systems, Inc., Minneapolis, $\mathrm{MN}$ ) according to the manufacturer's protocol. Absorbance was quantified using a Sunrise ELISA reader (Tecan Group Ltd., Zürich, Switzerland) with $450 \mathrm{~nm}$ as the primary wavelength, and the data were analyzed using Kim version 5.43.01 software (Daniel Kittrich - Software Production, Prague, Czech Republic).

\section{Statistical analysis}

The normality assumption was assessed using the Shapiro-Wilk test. Data are presented as the median with interquartile range (IQR). ANOVA with Bonferroni corrections, Spearman's correlation coefficient, Receiver operating curves (ROC), Area under the curve (AUC), and Fisher's exact test were used. $\mathrm{P}$ values less than 0.05 were considered statistically significant. All analyses and graphs were performed using GraphPad Prism 5.02 (GraphPad Software, La Jolla, CA, USA).

\section{Results}

\section{Clinical characteristic and treatment response}

All AS patients had high disease activity before commencing the anti-TNF therapy (BASDAI $>4$ and abnormal CRP) with a good therapeutic response at M3 and M12 based on CRP, ESR, BASDAI, and ASDAS (Table 1). All these parameters decreased significantly from M0 to M3 ( $<0.001$ for all comparisons) and remained significantly low at M12 $(\mathrm{p}<0.001$ for all comparisons). As expected, there were no significant 
A

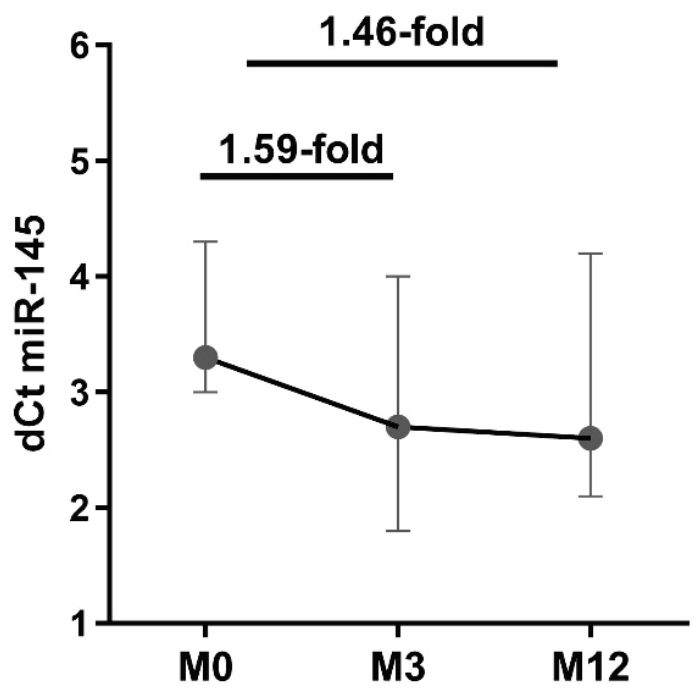

B

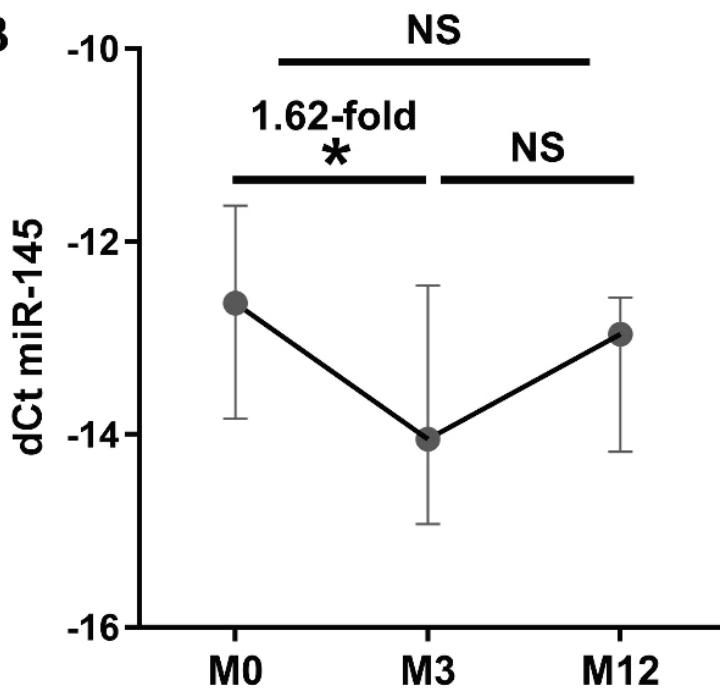

Fig. 1. Plasma expression of miR-145 at baseline, month 3, and month 12 of anti-TNF therapy. (A) Expression analyzed using comprehensive TaqMan Low Density array and (B) single assay validation. Data expressed as median with interquartile range. NS, not significant. * $\mathrm{p} \leq 0.05 \mathrm{dCt}$ was calculated as follows: (A) $\mathrm{dCt}=\mathrm{Ct}$ (array average)-Ct(miRNA of interest) and (B) Ct(spike-in average)$\mathrm{Ct}$ (miRNA of interest). Higher dCt values represent, therefore a higher expression of miR-145.

differences between M3 and M12 in any monitored parameters of disease activity $(\mathrm{p}>0.05$ for all comparisons).

\section{Analysis of miRNAs}

A comprehensive analysis of 380 circulating miRNAs in 3 patients was performed using TLDA, as described above. Out of the 380 miRNAs, 125 miRNAs were detected in all samples, while 148 miRNAs were detected at M0, 154 at M3, and 151 at M12. Only miRNAs expressed consistently in all samples below $\mathrm{Ct}$ cycle 30 and showing $>1.5$-fold change between at least 2 groups in initial analysis were taken for further validation (17 miRNAs in total). Single assay validation confirmed any difference between groups in the expression of 9 miRNAs (Thermo Fisher Scientific Assay Name: miR-16, miR-26b, miR-29a, miR-140, miR-1423p, miR-145, miR-150, miR-192, miR-374). However, only miR-145 (miRBase ID: has-miR-145-5p) showed significant changes from baseline to M3.

Given our interest in the predictive value of baseline or early change in miRNA expression for future outcomes in AS patients, only miR-145 was taken for further extended analysis. TLDA analysis of 3 samples revealed lower levels of circulating miR-145 at M3 (1.59-fold) and M12 (1.46-fold) compared to baseline (Fig. 1A). Next, single assay validation in 19 samples confirmed 1.62-fold lower expression of miR-145 at M3 compared to baseline $(p=0.024)$, but there were no significant differences after 12 months of therapy ( $>0.05$ ) (Fig. 1B).

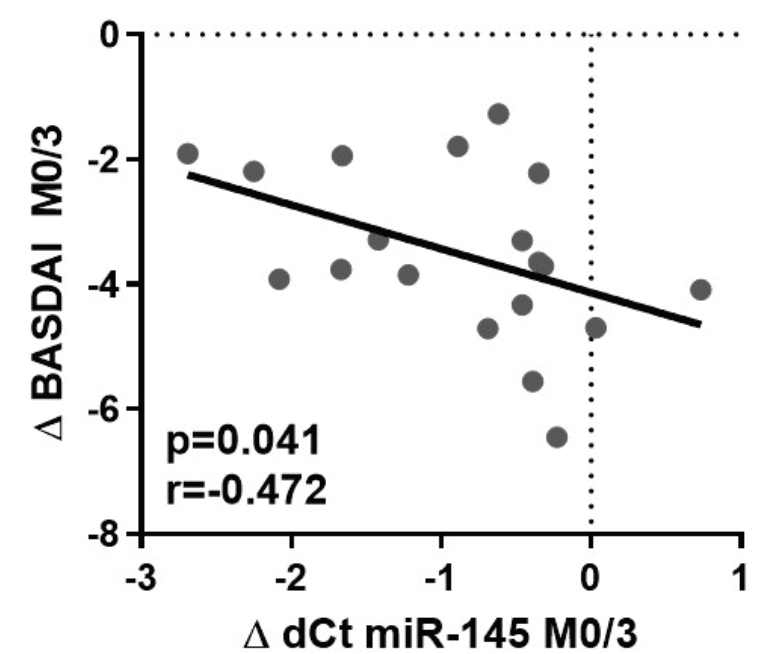

Fig. 2. Negative correlation between the change in miR-145 levels and BASDAI from month 0 to month 3. $\triangle$ dCt miR-145 $\mathrm{M0} / \mathrm{M} 3$ is calculated as M3-M0 (numbers $<0$ represent decreasing miRNA expression), $\triangle$ BASDAI M0/M3 is calculated as M3-M0 (numbers $<0$ represent the improvement of disease activity).

Early change in the expression of circulating miR-145 as a predictor of future outcome

The decrease in the levels of miR-145 from M0 to $\mathrm{M} 3$ in plasma is negatively associated with the change in BASDAI from M0 to M3 ( $p=0.041 ; r=-0.472$ ) (Fig. 2): the more significant decrease in miR-145 levels, the less improvement in BASDAI ( $\triangle \mathrm{BASDAI})$.

The disease outcome at M12 proved that the decrease in the miR-145 levels from M0 to M3 significantly positively correlated with disease activity improvement over time from M3 to M12 as per BASDAI 
$(p=0.002 ; r=0.672)$ and ASDAS $(p=0.006 ; r=0.607)$ (Fig. 3A). Therefore, patients with a more significant decrease in miR-145 levels associated with less initial improvement in BASDAI until M3 may show further significant improvement of BASDAI (and ASDAS) at M12. Importantly, this was further confirmed by ROC analysis. The ROC curves showed that the decrease in the miR-145 expression from M0 to M3 predicts the disease activity improvement from M3 to M12 defined by BASDAI (AUC [95\%CI] 0.807 [0.593 to 1.0], p=0.026), but not by ASDAS (AUC [95\%CI] 0.601 [0.439 to 0.925], $\mathrm{p}=0.186$ ) (Fig. 3B).

Furthermore, there was a positive correlation between the levels of miR-145 at M3 and disease outcome at M12: the lower levels of miR-145 at M3, the more improvement of disease activity from M3 to M12 and disease activity at M12 assessed by both BASDAI $(\triangle$ BASDAI: $\mathrm{p}=0.063 ; \mathrm{r}=0.435$ and BASDAI: $\mathrm{p}=0.071$; $\mathrm{r}=0.423$ ) and ASDAS ( $\triangle$ ASDAS: $\mathrm{p}=0.007$; $=0.593$ and ASDAS: $\mathrm{p}=0.019 ; \mathrm{r}=0.533$ ) (Fig. 4A). ROC analysis confirmed, that plasma levels of miR-145 at M3 significantly predicted low disease activity at M12 defined by BASDAI (cut off 4) (AUC [95\% CI] 0.896 [0.703 to 1.0]; $\mathrm{p}=0.034$ ) and ASDAS (cut of 2.1) (AUC [95 \% CI] 0.810 [0.564 to 1.0$] ; p=0.028$ ) (Fig. 4B), nevertheless it did not predict remission defined by ASDAS (cut off 1.3) (data not shown).

A
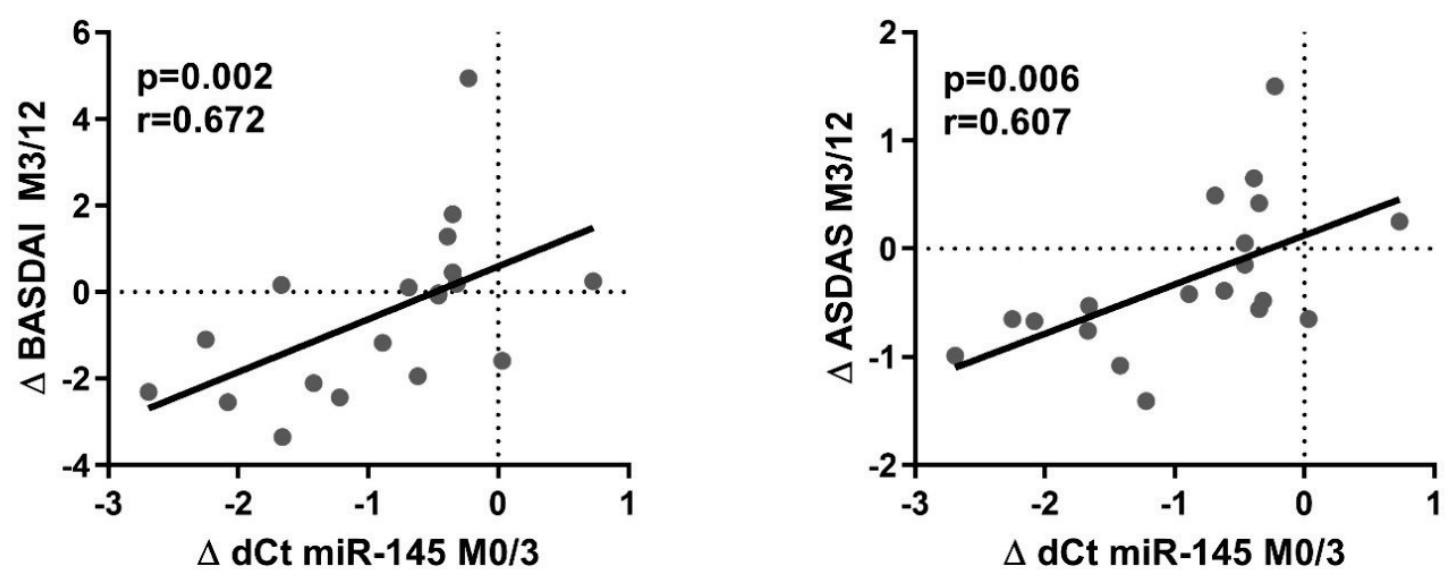

B

$\Delta$ miR-145 M0/3 vs. $\Delta$ BASDAI M3/12

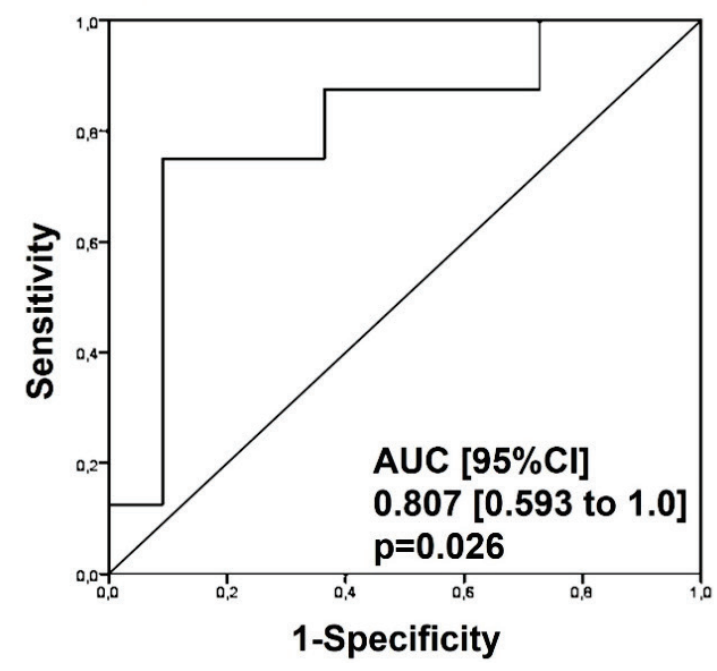

$\Delta$ miR-145 M0/3 vs. $\Delta$ ASDAS M3/12

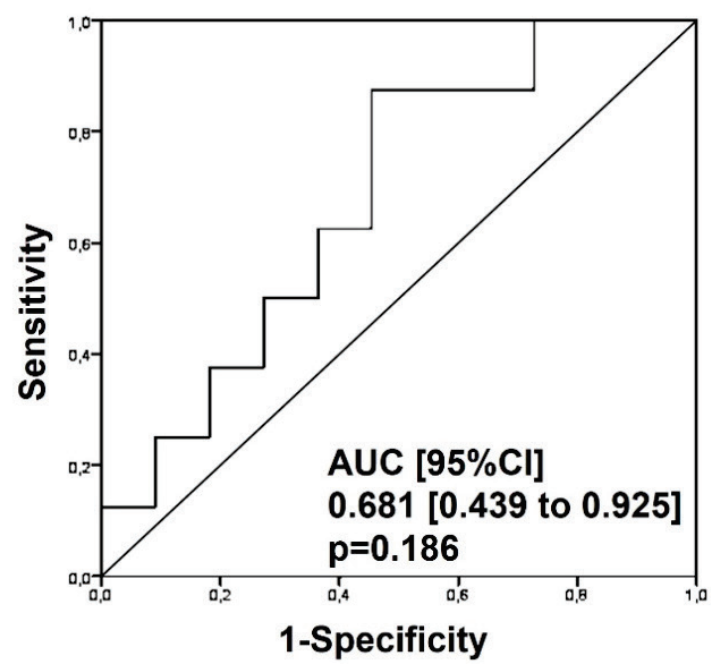

Fig. 3. Relationship between the early change in miR-145 expression from month 0 to month 3 and further clinical improvement from month 3 to 12. (A) Correlation of decreasing in miR-145 expression from M0 to M3 with disease activity improvement from M3 to M12. (B) ROC curves analysis of the change in miR-145 expression from M0 to M3 as a predictor of disease activity improvement from M3 to M12 defined by BASDAI and ASDAS. $\Delta$ dCt miR-145 M0/M3 is calculated as M3-M0 (numbers <0 represent decreasing miRNA expression), $\triangle$ BASDAI, and $\triangle$ ASDAS M3/M12 are calculated as M12-M3 (numbers $<0$ represent the improvement of disease activity). 
A
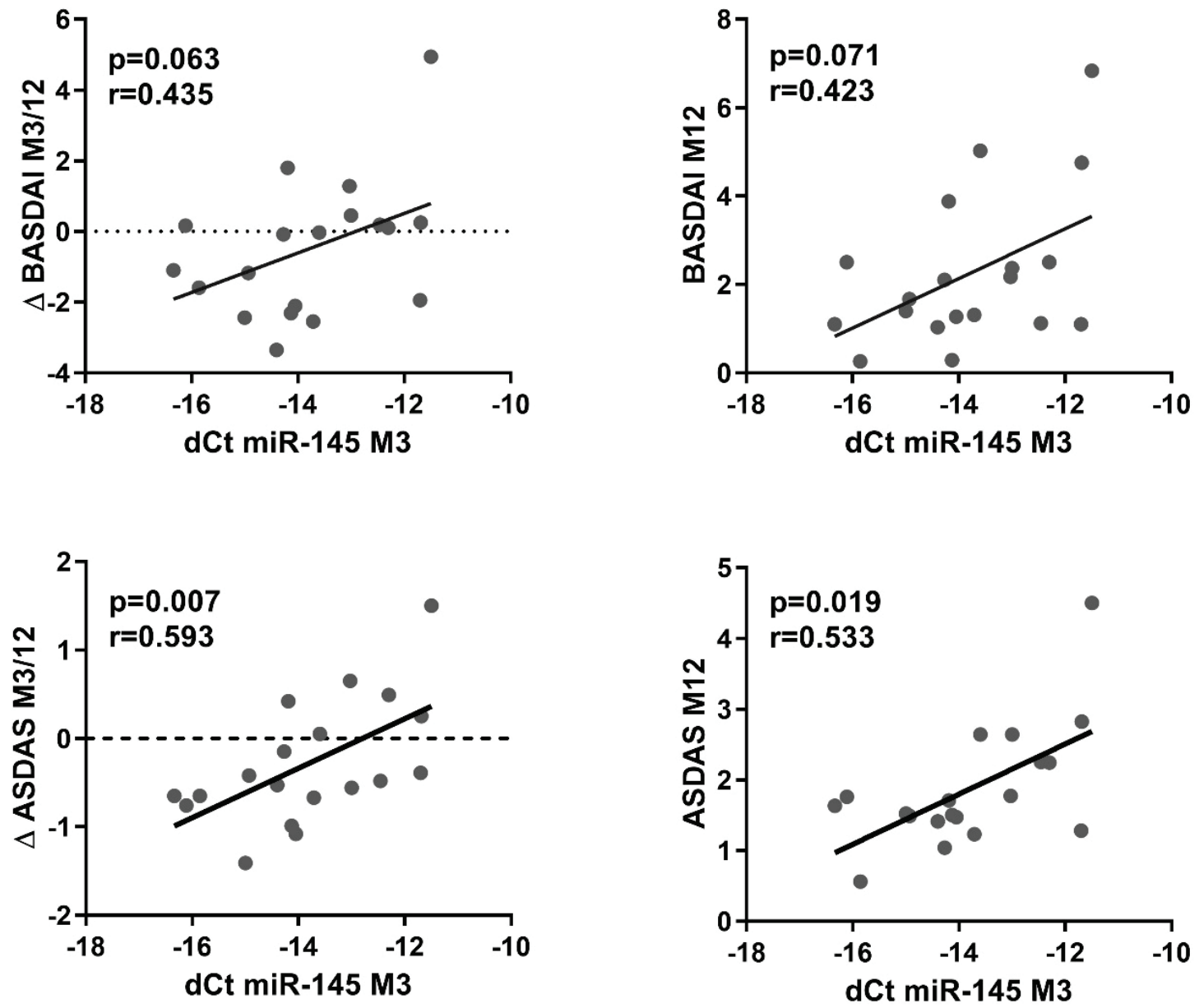

B

miR-145 M3 vs. BASDAI M12

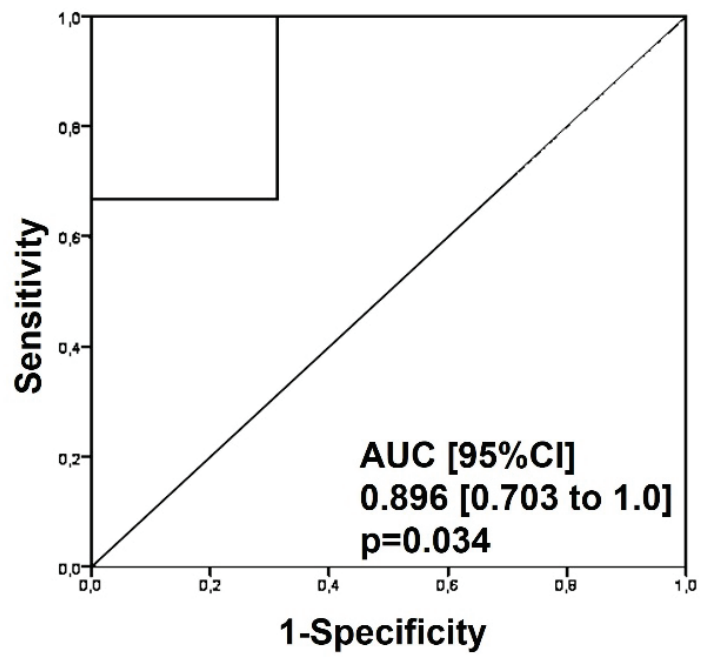

miR-145 M3 vs. ASDAS M12

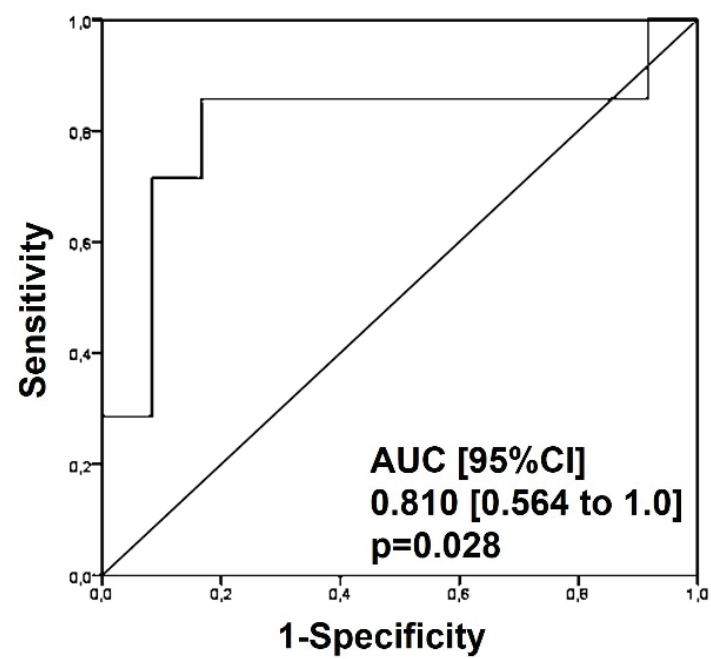

Fig. 4. Relationship between the expression of miR-145 in month 3 and disease activity outcome at month 12 . (A) Correlation of expression of miR-145 at M3 with disease activity outcome at M12. (B) Receiver operator characteristic (ROC) curves analysis of expression of miR145 at M3 as a predictor for the low disease activity at M12 defined by BASDAI $(<4)$ and ASDAS $(<2.1) . \Delta$ BASDAI and $\triangle$ ASDAS are calculated as BASDAI/ASDAS M12-M3 (numbers $<0$ represent the improvement of disease activity). 
Overall, as shown in Fig. 1, there was no significant change in miR-145 levels from M3 to M12. However, the plasma expression of miR-145 increased from M3 to M12 in 10 patients $(\mathrm{p}<0.001)$. In comparison to the remaining 9 patients whose miR-145 expression decreased from M3 to M12 ( $\mathrm{p}=0.004)$, these patients had significantly lower levels of miR-145 at M0 $(\mathrm{p}=0.044)$ and M3 ( $\mathrm{p}=0.002)$, although the levels of miR-145 at M12 were comparable $(p=0.164)$. Moreover, these patients had lower ASDAS at M0 $(\mathrm{p}=0.028), \mathrm{M} 3$ $(\mathrm{p}=0.006)$, and $\mathrm{M} 12(\mathrm{p}=0.010)$ and CRP at M12 $(\mathrm{p}=0.043)$, but there were no differences in BASDAI at any time (data not shown). There were no differences secondary to the biological agents used or between patients treated with monoclonal antibodies and etanercept ( $p>0.05)$. In the first group with increasing levels of miR-145 from M3 to M12, 7 patients were treated with monoclonal antibodies ( 2 with adalimumab, 4 with golimumab, and 1 with infliximab) and the remaining 3 with etanercept. In the second group, 7 patients were treated with monoclonal antibodies ( 1 with adalimumab, 1 with golimumab, and 5 with infliximab), and 2 were treated with etanercept.

VEGF and association with circulating miR-145 and treatment response

As VEGF was shown as a direct target of miR-145 (Fan et al. 2012), we were interested in its association with circulating miR-145 in plasma. There was a trend towards the decrease in VEGF levels from M0 to M3 ( $\mathrm{p}=0.069$ ), but there was no further change at M12 compared to M3. Levels of VEGF do not correlate with disease activity or its change at any time; however, the decrease in VEGF from M0 to M3 correlated with decreased CRP $(\mathrm{p}=0.001 ; \mathrm{r}=0.733)$ and $\mathrm{ESR}(\mathrm{p}=0.023$; $\mathrm{r}=0.517$ ) from $\mathrm{M} 0$ to $\mathrm{M} 3$. There was no correlation between the levels of VEGF and miR-145 at any time ( $>0.1$ for all comparisons) (data not shown).

\section{Discussion}

MicroRNAs are essential regulators of gene expression and therefore contribute to the physiology in health as well as to the pathophysiology of diseases, including inflammatory conditions (Filkova et al. 2012). Circulating miRNAs were shown to be very stable and easily accessible that makes them potential biomarkers (Cortez et al. 2011). Circulating miRNAs miR-23a-3p and miR-223-3p were previously described as biomarkers of therapeutic response to anti-TNF treatment in RA patients (Castro-Villegas et al. 2015). Regarding individuals with AS treated with anti-TNF therapy, however, there are only a few studies available related to miRNAs (Lv et al. 2015). Recently, circulating miR-5196 was shown to be decreased after anti-TNF therapy in AS patients, and change in the expression of miR-5196 correlated with disease activity improvement after treatment (Ciechomska et al. 2018). However, other studies on circulating miRNAs as markers of therapeutic response are lacking.

We analyzed the effect of anti-TNF therapy in AS patients on the expression of a wide range of circulating miRNAs. From the comprehensive analysis of miRNAs isolated from plasma, 17 miRNAs of a minimum 1.5-fold change difference were selected for further validation. From selected miRNAs, only miR-145 revealed a significant decrease from baseline to month three. There was still a significant decrease at month 12 compared to baseline, but there was no difference compared to month three.

Next, we validated the pilot data and assessed the relationship between miR-145 and the disease activity and treatment response in a larger patient cohort. We confirmed the decrease of miR-145 from baseline to M3 but no change from M3 to M12. We found that the more significant decrease in miR-145 expression correlated with poorer improvement of disease activity during the first 3 months. Importantly, our data showed that patients with a more significant reduction in miR-145 levels that is associated with the little improvement in BASDAI until month 3 may develop further significant improvement and better disease outcomes after 12 months of therapy based on BASDAI and ASDAS. The assessment of treatment response to anti-TNF treatment after 3 months is essential for further treatment decision making: whether the switch is indicated or the patient remains on the same drug. Based on our miR-145 data, we propose that the therapeutic switch after 3 months would be premature as some patients will improve significantly after 12 months on the same therapy.

We hypothesized a potential link between circulating miR-145 (and its reflection of disease outcome) in our AS patients with its possible involvement in the pathogenesis of AS. MiR-145 is known mainly as a tumor suppressor that mediates cell growth, invasion, and metastasis (Sachdeva and Mo, 2010). VEGF was shown to be increased in patients with 
AS compared to healthy controls and decreased following anti-TNF therapy (Pedersen et al. 2010). VEGF is a crucial mediator in angiogenesis, is involved in osteogenesis, and, therefore, bone remodeling ( $\mathrm{Hu}$ and Olsen 2016) and was previously described as a direct target gene of miR-145 (Fan et al. 2012). Although we proved the decrease in systemic VEGF after anti-TNF therapy, as shown previously (Pedersen et al. 2010), we showed no associations between circulating miR-145 and VEGF.

The characteristic inflammation of spondyloarthritis occurs at the interface between cartilage and bone in the sacroiliac joints, the spine, and the entheses. The mechanisms of interaction between inflammation, paradoxical bone destruction, and new bone formation are still not completely understood. However, studies have suggested that the initial inflammation (in which TNF is the principal cytokine involved) causes erosions in cartilage and bone; these lesions are then filled in by fibrous tissue, that is later ossified, leading to abnormal bony growth (syndesmophytes, bone bridges, and complete ankyloses) (Sieper and Poddubnyy 2017, Watad et al. 2018, Cici et al. 2019). Undoubtedly, the Wnt (Wingless) signaling pathway is considered one of the primary regulators of bone metabolism. It is involved in osteoblast differentiation from mesenchymal precursors and osteoprogenitor cells, osteoblast regulation, proliferation, and survival (Cici et al. 2019). MiR-145 was shown to negatively regulate chondrogenesis and bone formation (osteogenic differentiation, osteoblastogenesis or bone regeneration) at multiple levels of Wnt signaling and other bone-homeostasis related mechanisms (Jia et al. 2013, Yang et al. 2011, Hao et al. 2018, Fukuda et al. 2015) and to aggravate bone erosions by promoting osteoclastogenesis (Chen et al. 2018). We, therefore, suggest that our data may reflect the involvement of miR-145 in bone-remodeling in AS. In fact, in our previous work, we showed lower levels of miR-145 in plasma of AS patients than healthy controls and between non-radiographic AxSpA and advanced AS stages (Prajzlerova et al. 2017). We hypothesize that the decrease in miR-145 levels in the first 3 months of antiTNF therapy can reflect the shift from the initial erosive process to the induction of reparative mechanisms represented by new bone formation. In our study, these could be reflected by further improvement in BASDAI score during follow-up.
Despite presenting miR-145 as a predictor of future response to anti-TNF therapy, our study has some limitations. Firstly, our data show the association of miR-145 with a short-term disease outcome in advanced disease (most AS patients had cervical spine involvement). The predictive value of miR-145 for radiographic progression is missing and would need longterm follow up. Similarly, analysis of miR-145 in the non-radiographic disease would undoubtedly be of interest as well, although our previous study showed no difference in miR-145 between healthy controls and non-radiographic AxSpA. Our data also need validation in larger patient cohorts. The data from published in vitro and in vivo studies show different roles of miR-145 in inflammation or bone formation. Our data are descriptive and show no association with selected mediators of inflammation or tissue remodeling (e.g., CRP or VEGF). We can only hypothesize the exact role of miR-145 in the pathogenesis of AS and, especially, which pathophysiologic aspect of TNF inhibition is reflected by changes in circulating miR-145 in patients with AS. Although bone-remodeling appears suggestive, we are unable to directly prove this as we didn't look directly at the tissues of interest, and also, when circulating miRNAs are studied, they may originate from different cells or tissues and reflect various more or less specific tissuerelated pathways.

To conclude, we show that the early change in circulating miR-145 may be a predictor for the future outcome of AS patients treated with anti-TNF inhibitors. Patients with a more significant decrease in miR-145 levels may show further significant improvement of disease activity after 12 months. Monitoring the expression of miR-145 in plasma in AS patients may, therefore, influence our therapeutic decision-making.

\section{Conflict of Interest}

There is no conflict of interest.

\section{Acknowledgements}

This work was supported by a grant 17-33127A of the Agency for Healthcare Research of the Czech Republic and a project of the MHCR for conceptual research development No. 023728.

There is no financial support or other benefits from commercial sources for the work reported in the manuscript. 


\section{References}

BRANDT J, HAIBEL H, CORNELY D, GOLDER W, GONZALEZ J, REDDIG J, THRIENE W, SIEPER J, BRAUN $\mathrm{J}$ : Successful treatment of active ankylosing spondylitis with the anti-tumor necrosis factor alpha monoclonal antibody infliximab. Arthritis Rheum 43: 1346-1352, 2000. https://doi.org/10.1002/15290131(200006)43:6<1346::AID-ANR18>3.0.CO;2-E

BRAUN J, VAN DER HEIJDE D, DOUGADOS M, EMERY P, KHAN MA, SIEPER J, VAN DER LINDEN S: Staging of patients with ankylosing spondylitis: a preliminary proposal. Ann Rheum Dis 61 (Suppl 3): iii9-iii23, 2002. https://doi.org/10.1136/ard.61.suppl 3.iii19

CASTRO-VILLEGAS C, PEREZ-SANCHEZ C, ESCUDERO A, FILIPESCU I, VERDU M, RUIZ-LIMON P, AGUIRRE MA, JIMENEZ-GOMEZ Y, FONT P, RODRIGUEZ-ARIZA A, PEINADO JR, COLLANTESESTEVEZ E, GONZALEZ-CONEJERO R, MARTINEZ C, BARBARROJA N, LOPEZ-PEDRERA C: Circulating miRNAs as potential biomarkers of therapy effectiveness in rheumatoid arthritis patients treated with anti-TNFalpha. Arthritis Res Ther 17: 49, 2015. https://doi.org/10.1186/s13075-015-0555-Z

CICI D, CORRADO A, ROTONDO C, CANTATORE FP: Wnt Signaling and Biological Therapy in Rheumatoid Arthritis and Spondyloarthritis. Int J Mol Sci 20: 5552 2019. https://doi.org/10.3390/ijms20225552

CIECHOMSKA M, BONEK K, MERDAS M, ZARECKI P, SWIERKOT J, GLUSZKO P, BOGUNIA-KUBIK K, MASLINSKI W: Changes in MiRNA-5196 Expression as a potential biomarker of anti-TNF-alpha therapy in rheumatoid arthritis and ankylosing spondylitis patients. Arch Immunol Ther Exp (Warsz) 66: 389-397, 2018. https://doi.org/10.1007/s00005-018-0513-y

CORTEZ MA, BUESO-RAMOS C, FERDIN J, LOPEZ-BERESTEIN G, SOOD AK, CALIN GA: MicroRNAs in body fluids--the mix of hormones and biomarkers. Nat Rev Clin Onco 8: 467-477, 2011. https://doi.org/10.1038/nrclinonc.2011.76

DLOUHA D, HUBACEK JA: Regulatory RNAs and cardiovascular disease - with a special focus on circulating microRNAs. Physiol Res 66: S21-S38, 2017. https://doi.org/10.33549/physiolres.933588

FAN L, WU Q, XING X, WEI Y, SHAO Z: MicroRNA-145 targets vascular endothelial growth factor and inhibits invasion and metastasis of osteosarcoma cells. Acta Biochim Biophys Sin (Shanghai) 44: 407-414, 2012. https://doi.org/10.1093/abbs/gms019

FILKOVA M, ARADI B, SENOLT L, OSPELT C, VETTORI S, MANN H, FILER A, RAZA K, BUCKLEY CD, SNOW M, VENCOVSKY J, PAVELKA K, MICHEL BA, GAY RE, GAY S, JUNGEL A: Association of circulating miR-223 and miR-16 with disease activity in patients with early rheumatoid arthritis. Ann Rheum Dis 73: 1898-1904, 2014. https://doi.org/10.1136/annrheumdis-2012-202815

FILKOVA M, JUNGEL A, GAY RE, GAY S: MicroRNAs in rheumatoid arthritis: potential role in diagnosis and therapy. BioDrugs 26: 131-141, 2012. https://doi.org/10.2165/11631480-000000000-00000

FUKUDA T, OCHI H, SUNAMURA S, HAIDEN A, BANDO W, INOSE H, OKAWA A, ASOU Y, TAKEDA S: MicroRNA-145 regulates osteoblastic differentiation by targeting the transcription factor Cbfb. FEBS Lett589: 3302-3308, 2015. https://doi.org/10.1016/i.febslet.2015.09.024

GARRETT S, JENKINSON T, KENNEDY LG, WHITELOCK H, GAISFORD P, CALIN A: A new approach to defining disease status in ankylosing spondylitis: the Bath Ankylosing Spondylitis Disease Activity Index. J Rheumatol 21: 2286-2291, 1994.

HAO W, LIU H, ZHOU L, SUN Y, SU H, NI J, HE T, SHI P, WANG X: MiR-145 regulates osteogenic differentiation of human adipose-derived mesenchymal stem cells through targeting FoxO1. Exp Biol Med (Maywood) 243: 386-393, 2018. https://doi.org/10.1177/1535370217746611

HAROON N, INMAN RD, LEARCH TJ, WEISMAN MH, LEE M, RAHBAR MH, WARD MM, REVEILLE JD, GENSLER LS: The impact of tumor necrosis factor alpha inhibitors on radiographic progression in ankylosing spondylitis. Arthritis Rheum 65: 2645-2654, 2013. https://doi.org/10.1002/art.38070

HRUSKOVA V, JANDOVA R, VERNEROVA L, MANN H, PECHA O, PRAJZLEROVA K, PAVELKA K, VENCOVSKY J, FILKOVA M, SENOLT L: MicroRNA-125b: association with disease activity and the treatment response of patients with early rheumatoid arthritis. Arthritis Res Ther 18: 124, 2016. https://doi.org/10.1186/s13075-016-1023-0 
HU K, OLSEN BR: The roles of vascular endothelial growth factor in bone repair and regeneration. Bone 91: 30-38, 2016. https://doi.org/10.1016/j.bone.2016.06.013

CHEN Y, WANG X, YANG M, RUAN W, WEI W, GU D, WANG J, GUO X, GUO L, YUAN Y: miR-145-5p increases osteoclast numbers in vitro and aggravates bone erosion in collagen-induced arthritis by targeting osteoprotegerin. Med Sci Monit 24: 5292-5300, 2018. https://doi.org/10.12659/MSM.908219

JIA J, TIAN Q, LING S, LIU Y, YANG S, SHAO Z: miR-145 suppresses osteogenic differentiation by targeting Sp7. FEBS Lett 587: 3027-3031, 2013. https://doi.org/10.1016/j.febslet.2013.07.030

LUKAS C, LANDEWE R, SIEPER J, DOUGADOS M, DAVIS J, BRAUN J, VAN DER LINDEN S, VAN DER HEIJDE D: Development of an ASAS-endorsed disease activity score (ASDAS) in patients with ankylosing spondylitis. Ann Rheum Dis 68: 18-24, 2009. http://dx.doi.org/10.1136/ard.2008.094870

LV Q, LI Q, ZHANG P, JIANG Y, WANG X, WEI Q, CAO S, LIAO Z, LIN Z, PAN Y, HUANG J, LI T, JIN O, WU Y, GU J: Disorders of microRNAs in peripheral blood mononuclear cells: as novel biomarkers of ankylosing spondylitis and provocative therapeutic targets. Biomed Res Int 2015: 504208, 2015. https://doi.org/10.1155/2015/504208

MACHADO P, LANDEWE R, BRAUN J, HERMANN KG, BAKER D, VAN DER HEIJDE D: Both structural damage and inflammation of the spine contribute to impairment of spinal mobility in patients with ankylosing spondylitis. Ann Rheum Dis 69: 1465-1470, 2010. https://doi.org/10.1136/ard.2009.124206

PEDERSEN SJ, HETLAND ML, SORENSEN IJ, OSTERGAARD M, NIELSEN HJ, JOHANSEN JS: Circulating levels of interleukin-6, vascular endothelial growth factor, YKL-40, matrix metalloproteinase-3, and total aggrecan in spondyloarthritis patients during 3 years of treatment with TNFalpha inhibitors. Clin Rheumatol 29: 1301-1309, 2010. https://doi.org/10.1007/s10067-010-1528-x

PRAJZLEROVA K, GROBELNA K, HUSAKOVA M, FOREJTOVA S, JUNGEL A, GAY S, VENCOVSKY J, PAVELKA K, SENOLT L, FILKOVA M: Association between circulating miRNAs and spinal involvement in patients with axial spondyloarthritis. PLoS One12: e0185323, 2017. https://doi.org/10.1371/journal.pone.0185323

PRAJZLEROVA K, GROBELNA K, PAVELKA K, SENOLT L, FILKOVA M: An update on biomarkers in axial spondyloarthritis. Autoimmun Rev 15: 501-509, 2016. https://doi.org/10.1016/j.autrev.2016.02.002

RUDWALEIT M, LANDEWE R, VAN DER HEIJDE D, LISTING J, BRANDT J, BRAUN J, BURGOS-VARGAS R, COLLANTES-ESTEVEZ E, DAVIS J, DIJKMANS B, DOUGADOS M, EMERY P, VAN DER HORSTBRUINSMA IE, INMAN R, KHAN MA, LEIRISALO-REPO M, VAN DER LINDEN S, MAKSYMOWYCH WP, MIELANTS H, OLIVIERI I, STURROCK R, DE VLAM K, SIEPER, J: The development of Assessment of SpondyloArthritis international Society classification criteria for axial spondyloarthritis (part I): classification of paper patients by expert opinion including uncertainty appraisal. Ann Rheum Dis 68: 770-776, 2009. https://doi.org/10.1136/ard.2009.108217

SACHDEVA M, MO YY: miR-145-mediated suppression of cell growth, invasion and metastasis. Am J Transl Res 2: 170-180, 2010.

SIEPER J, PODDUBNYY D: Axial spondyloarthritis. Lancet 390: 73-84, 2017. https://doi.org/10.1016/S0140$\underline{6736(16) 31591-4}$

TAUROG JD, CHHABRA A, COLBERT RA: Ankylosing spondylitis and axial spondyloarthritis. N Engl J Med 375: 1303, 2016. https://doi.org/10.1056/NEJMc1609622

VAN DER LINDEN S, VALKENBURG HA, CATS A: Evaluation of diagnostic criteria for ankylosing spondylitis. A proposal for modification of the New York criteria. Arthritis Rheum 27: 361-368, 1984. https://doi.org/10.1002/art.1780270401

WATAD A, BRIDGEWOOD C, RUSSELL T, MARZO-ORTEGA H, CUTHBERT R, MCGONAGLE D: The early phases of ankylosing spondylitis: emerging insights from clinical and basic science. Front Immunol 9: 2668, 2018. https://doi.org/10.3389/fimmu.2018.02668

YANG B, GUO H, ZHANG Y, CHEN L, YING D, DONG S: MicroRNA-145 regulates chondrogenic differentiation of mesenchymal stem cells by targeting Sox9. PLoS One 6: e21679, 2011. https://doi.org/10.1371/journal.pone.0021679 